\title{
Energy poverty, crisis and austerity in Spain
}

\author{
Sergio Tirado Herrero ${ }^{1 *}$ and Luis Jiménez Meneses ${ }^{2}$ \\ 1 RMIT Europe / The University of Manchester / Asociación de Ciencias Ambientales \\ 2 Asociación de Ciencias Ambientales
}

\begin{abstract}
Despite clear indications about its significance, a systematic examination of the connection between the European debt crisis and domestic energy affordability trends is still missing in the academic and policy literature. This paper seeks to provide an empirically-grounded investigation of crisis and austerity as macro-scale driving factors of energy poverty, taking Spain as a case study. For this, a range of data and indicators are presented for the period 2004-2012. They provide evidence of the increase in domestic energy deprivation levels in Spain since 2008 that occurred in parallel with a rapid surge in unemployment rates and domestic energy prices, especially of electricity. Collected evidence also indicates substantial differences in energy poverty levels across Spanish regions (Autonomous Communities) linked to disparities in climatic and socio-economic conditions, including unemployment. Resulting energy poverty levels are understood as a consequence of structural and short-term factors operating along pre-existing socio-spatial cleavages exacerbated by the crisis.
\end{abstract}

Key words: energy poverty, crisis, austerity, unemployment, Spain.

\section{Introduction}

The recession that turned into a fully-fledged global financial and economic crisis in the early days of September 2008 has had and continues to have far-reaching consequences on the welfare and livelihoods of millions of Europeans. The initial 'credit crunch' and its subsequent knock-on effects on key macroeconomic variables such as per capita GDP and unemployment rates quickly translated into diminished living conditions and growing levels of inequality and deprivation that still persist. In some Southern and Eastern EU Member States these impacts were more intense given their weaker economic fundamentals and levels of exposure to external shocks. This was particularly the case for a number of credit-dependant economies of the Eurozone (Cyprus, Greece, Ireland, Portugal and Spain) that have been forced to adopt austerity measures under the supervision of a 'troika' of supra-national institutions - the European Commission, the European Central Bank and the International Monetary Fund. 
In Spain, a combination of external factors and internal economic decision-making resulted in negative GDP growth rates for several years in a row from 2009 onwards and the number of unemployed climbed from 1.8 million to 6.1 million people between 2006 and 2013 (INE, 2015). This sequence of events is having far-reaching consequences for the wellbeing of Spaniards as evidenced, for instance, by the rising incidence of various mental health disorders, especially among citizens experiencing household unemployment and mortgage payment difficulties (Gili et al., 2013; Urbanos-Garrido and Lopez-Valcarcel, 2015).

One of the many ways in which the European debt crisis has affected the day-to-day lives of Europeans is through energy (or fuel) poverty - note that 'energy poverty' is used throughout the paper as it more clearly encompasses all domestic services of energy (and not only those based on 'fuels') and also because it is more widely used across continental Europe. Understood as a condition in which households are unable to access socially- and materially-necessitated levels of domestic energy services (Bouzarovski and Petrova, 2015), the new conditions brought forward by the crisis have exacerbated pre-existing vulnerabilities arising from structural inequalities and poverty, rising energy prices, uneven household energy needs, lack of comprehensive policies, and poor energy performance of residential buildings. EU institutions are aware of these links, as indicated, for example, by the opinion document of the European Economic and Social Committee 'Energy poverty - the impact of liberalisation and the economic crisis' in which the following is quoted:

The economic and financial crisis that started in 2007 occurred against a backdrop in which European workers' pay was stagnating or falling. Furthermore, the economic measures proposed in some Member States to reduce the high level of debt and the public deficit are having an effect on social security benefits (such as pensions and unemployment benefits, for example) and on public services. [...] All of this creates a worrying outlook for the households that are most vulnerable in the face of rising energy prices. (Santillán Cabeza, 2010)

Largely an unrecognised issue in Spain until the late 2000s, energy poverty started to attract attention as a distinct policy subject and entered public debate partially as a result of the publication of the report 'Energy poverty in Spain. Potential for direct employment generation of residential energy efficiency retrofits' by the Asociación de Ciencias Ambientales (Tirado Herrero et al., 2012). By early 2014 the Congress of Deputies, Spain's legislative branch, and regional parliaments in 11 of the 17 Autonomous Communities - the key second-tier governance and administrative level of quasi-federal Spain - had registered legislative action explicitly mentioning energy poverty, with a range of local councils also launching initiatives at the city level (Tirado Herrero et al., 2014). In parallel, a number of advocacy and civil society organisations such as the Alianza contra la Pobreza Energética and the Plataforma por un Nuevo Modelo Energético have either emerged anew or adopted energy poverty as a central claim within wider demands for a democratic, de-centralised and renewable-based energy provision system in Spain while engaging in fierce criticism of large energy corporations.

Prior to these, the EU-funded European fuel Poverty and Energy Efficiency (EPEE) project had conducted the first empirical assessment of the issue in Spain as part of a larger cross-country revision primarily based on the EU Survey on Income and Living Conditions (Nolay, 2009). More recently, the Economics for Energy think-tank has presented a comprehensive assessment of expenditure-based metrics that explores a range of methodological options including the first implementation of the UK's official fuel poverty definition - the Low Income-High Costs (LIHC) indicator - to the Spanish context (Romero et al., 2014). In spite of these efforts, a proper investigation on how 
the economic crisis and subsequent austerity relate to the rise of energy poverty levels in Spain and the EU as a whole is still missing.

Against this backdrop, this paper has two main aims. First, it explores the incidence and evolution of energy poverty in Spain in the period 2004-2012, thus offering the possibility of an empirically-grounded assessment of crisis and austerity as macro-scale vulnerability factors in Member States. Second, it examines energy poverty as a spatially uneven phenomenon taking Spain's territorial division into Autonomous Communities as scale of analysis. It also examines the connection between domestic energy deprivation levels with energy prices and unemployment rates - two suspected key short-term drivers of energy poverty rates during the crisis. In doing so, the paper brings to an academic audience the main findings of the report 'Energy poverty in Spain 2014. Analysis of trends' (Tirado Herrero et al., 2014).

\section{Energy poverty, crisis and austerity in the EU}

A central assumption of this paper is that the economic crisis and the subsequent austerity-driven economic policies implemented in the EU are enhancing domestic energy-related vulnerabilities as they create a new set of conditions under which households are more likely to suffer from domestic energy deprivation. Taking Greece as a prime example of austerity-ridden EU economies, research has shown that the crisis has resulted in higher levels of arrears or non-payment of utility bills (Dagoumas and Kitsios, 2014), has decreased actual energy use per square metre of dwelling (Santamouris et al., 2013) and has led to a return of solid fuel-based space heating (Knight, 2014).

Decisions taken by national Governments subject to austerity have had wider implications across energy capture and provision systems that reinforce existing vulnerabilities and create new ones. Again in Greece, raising heating oil taxes - one of the many fiscal consolidation measures implemented in this country - led to an increase in the use of electricity for domestic space heating (Dagoumas and Kitsios, 2014). Adding further layers of complexity, fiscal consolidation has resulted too in the withdrawal of resources previously available for the de-carbonisation of the global economy (Falkner, 2014), threatening one of the main pathways of the 'energy transition'- the subsidisation of low-carbon options.

Crisis and related austerity policies map over pre-existing disparities and therefore are having uneven impacts across Member States. 'Regions' of energy poverty have been defined in the EU, with Southern and Eastern Member States reporting higher levels of domestic thermal discomfort and arrears on utility bills (Healy, 2004; Thomson and Snell, 2013). More recently, the possibility of an 'energy divide' in the EU has been interrogated in which periphery countries of Central and Eastern Europe and the Mediterranean suffer (though not in all cases) from systemic levels of energy poverty affecting both low- and middle-income strata and 'dynamics of crisis-induced austerity and post-communist transformation' (Bouzarovski and Tirado Herrero, 2015). At the Member State level, mountainous regions have been identified as especially vulnerable given their higher thermal comfort needs and relative lack of incomeearning opportunities even if the presence of locally-available resources such as firewood enhances the resilience of populations (Katsoulakos, 2011). Collected evidence thus suggests that energy-related vulnerabilities overlap with pre-existing social and spatial cleavages resulting in a complex and multi-scalar geography of domestic energy deprivation. 


\section{Data and methods}

This empirical paper relies primarily on expenditure-based and self-reported indicators that have become common practice in the quantitative assessment of energy poverty. Neither of the two approaches is deemed superior as we assume that they both are 'proxies' providing information on a diversity of household experiences, practices and hardships comprehended under the energy poverty label.

Expenditure-based indicators are based on the 'energy burden', i.e., actual domestic energy expenditures as a proportion of household income. Energy burdens have been calculated from microdata (anonymised expenditure and income data of individuallysurveyed households) of the Spanish Household Budget Survey (HBS). For this we have assumed that the same equivalisation factors can be applied to household income and energy expenditures. Because of limitations of the available HBS data our energy burdens rely on actual energy expenditure, which most likely underestimates energy poverty rates when compared to calculations-based on required energy expenditures (to maintain a certain level of thermal comfort), as in UK official fuel poverty statistics (Hills, 2012), where datasets allow for this. We also do not consider before-housing costs income, which makes households living in locations with higher housing costs (such as cities) appear less prone to experiencing high energy burdens. However, it is believed that our calculations provide an accurate enough indication of domestic energy affordability in their context.

Self-reported indicators (Healy, 2004) are based on microdata of the Survey on Income and Living Conditions (SILC). They provide a direct assessment of certain aspects of the experience of energy poverty as perceived by surveyed households themselves, which calls for a word of caution given their subjective and culturallydependent nature (Healy, 2004; Petrova et al., 2013).

The analysis also uses official per capita GDP and unemployment rate statistics disaggregated by Autonomous Communities for 2012 also retrieved from the Spanish National Statistics Institute. In addition, annual prices of natural gas and electricity for residential consumers in the period 2007-2012 have been obtained from Eurostat.

Annual average energy prices and values of energy poverty indicators are plotted for the period 2004/2006/2007 to 2012 with the aim of analysing trends in domestic energy deprivation factors and outcomes before and throughout the crisis. In order to further explore the relationship amongst energy poverty indicators, and with the unemployment rate, we use cross-tabulation figures and linear correlation analysis (Pearson's r).

\section{Results: temporal and spatial trends in energy poverty levels and driving factors}

\section{Energy (electricity) prices and household incomes}

Among the various factors driving the evolution of energy poverty levels, household income and domestic energy prices, especially of electricity, are the main focus of our short-term analysis for 2006-2012. Electricity is a main focus of the analysis as it is a key component of Spain's domestic energy demand and the most costly item of the average household's energy bill. In addition, many Spanish households still rely on electricity-based heating when the dwelling does not have a pre-installed heating system. 
Major trends in these two key variables are shown in Figure 1. According to the author's own calculations, if in 2008 the average household reported an annual income of $€ 24,474$, by 2012 this had dropped to $€ 22,413$. The decline was exacerbated by the fact that inflation rates in that period, though moderate, were positive, which effectively reduced actual purchasing powers beyond what figures in current Euros suggest. In the meantime, average household annual energy expenditure went from $€ 768$ (€851 in 2008) to $€ 1,135$ per year in 2012. This increase also expressed in current Euros is likely masking the fact that households, especially vulnerable ones, have adopted coping strategies such as the rationing of domestic energy consumption in the context of shrinking income levels and rising energy prices during the crisis.

A main reason for the sustained decrease of income levels is unemployment, which escalated from a record low of 7.9 per cent registered in the second quarter of 2007 to 25.8 per cent in the last quarter of 2012 (INE, 2015). The surge in unemployment rates accelerated later on following the 2012 labour market reform that allowed companies greater flexibility in the organisation of their workforce, introduced changes to the collective bargain agreement system and significantly reduced severance costs paid by employers. These changes primarily affected laid-off workers but also pushed down the wages of new and returning workers and of those who retained their employment. The burden of dismissals and wage adjustment was unevenly distributed across the labour force and disproportionately affected workers in construction and related industries, workers with temporary contracts and new entrants to the labour market, thus increasing the precariousness of those in a less privileged position (García Serrano, 2011; Martín Urriza et al., 2015; Orsini, 2014). Other austerity-related decisions such as the reduction in public sector wages and the freezing of pensions (Carballo-Cruz, 2011) also contributed to reduce the purchasing power of Spanish households. These measures are main components of the 'internal devaluation' of prices and salaries endorsed by EU institutions and implemented by successive Spanish Governments faced with the impossibility of a unilateral devaluation of the Euro. They also point at social segments - such as unskilled and temporary workers, youth and pensioners - that have become more vulnerable to various forms of material deprivation as a result of the crisis.

On the side of domestic energy costs, the rise in average electricity expenses (see Figure 1) is the most significant trend. Even if this increase can be partially attributed to a further 'electrification' of domestic energy services, a main driver is the evolution of prices per kWh, which experienced a 63 per cent nominal increase in 2006-2012 versus a 26 per cent rise in the EU28 (see Table 1). Unsurprisingly, Spain reported the sixth highest electricity price in the EU as of the end of 2012. The price of natural gas, another main 'energy carrier' used by Spanish households, remained stable until a significant increase occurred between 2011 and 2012. 
Figure 1: Evolution of average household income and domestic energy expenditure (total and disaggregated by energy carriers) in Spain 2006-2012, current Euros per year referred to the index $2006=100$ for comparative purposes

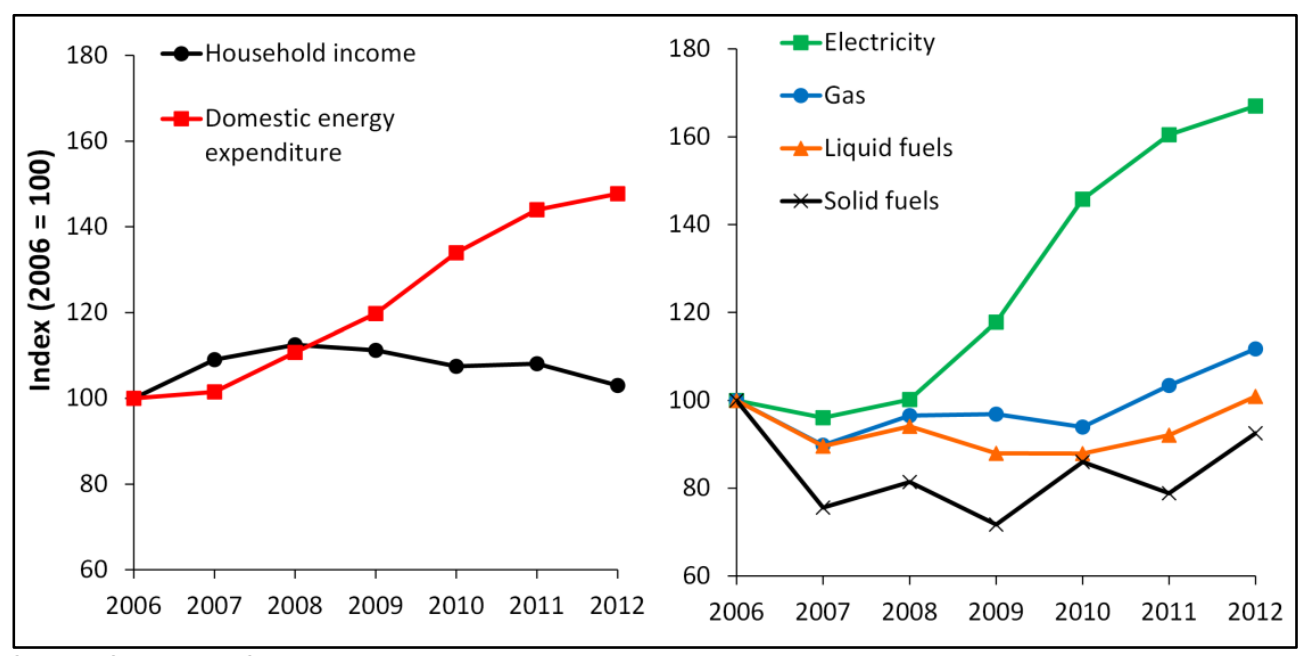

Source: Spanish HBS

Table 1: Price of electricity and natural gas for average domestic consumers (Spain vs EU28 in 2007-2012) in current Euros per kWh, and percentage of change in prices between 2007 and 2012

\begin{tabular}{|l|l|l|l|l|l|l|l|}
\hline Electricity & $\mathbf{2 0 0 7}$ & $\mathbf{2 0 0 8}$ & $\mathbf{2 0 0 9}$ & $\mathbf{2 0 1 0}$ & $\mathbf{2 0 1 1}$ & $\mathbf{2 0 1 2}$ & \% of change \\
\hline EU28 & 0.156 & 0.166 & 0.164 & 0.173 & 0.184 & 0.196 & $26 \%$ \\
\hline Spain & 0.140 & 0.156 & 0.168 & 0.185 & 0.209 & 0.228 & $63 \%$ \\
\hline Natural gas & $\mathbf{2 0 0 7}$ & $\mathbf{2 0 0 8}$ & $\mathbf{2 0 0 9}$ & $\mathbf{2 0 1 0}$ & $\mathbf{2 0 1 1}$ & $\mathbf{2 0 1 2}$ & \% of change \\
\hline EU28 & 0.051 & 0.062 & 0.052 & 0.057 & 0.065 & 0.070 & $37 \%$ \\
\hline Spain & 0.058 & 0.065 & 0.054 & 0.054 & 0.054 & 0.086 & $49 \%$ \\
\hline
\end{tabular}

Source: Eurostat

Note: average domestic consumers for electricity defined by consumption band 2,500 to 5,000 kWh per year; for natural gas the equivalent consumption band is 20 to $200 \mathrm{GJ}$ per year.

Given the regulated character of domestic electricity prices in Spain, their evolution cannot be separated from economic policy decisions taken before and after 2008 . Following the liberalisation of the energy sector in late 1990s, electricity prices are currently made up of two main components. One is generation costs determined in wholesale market auctions by electricity producers. The second component is regulated costs set by the Government. These include transmission and distribution costs, 'extrapeninsular' costs (i.e., subsidies to Balearic and Canary islands residents justified by higher generation costs in Spanish overseas territories) and subsidies for renewables and co-generation. Since 2000, rates charged to electricity consumers have been below cost-recovery levels, resulting in the so-called 'electricity tariff deficit' that has grown steadily until reaching €30 billion in 2013 (Johanesson Linden et al., 2014). Both components of electricity prices (generation and regulated costs) and the 'electricity tariff deficit' are highly contentious and subject to recurrent political debate.

Renewable feed-in tariffs have often been blamed for the 'electricity tariff deficit', as costs of support to these technologies increased from €1.2 billion per year in 2005 to $€ 8.4$ billion in 2012 (Johanesson Linden et al., 2014). However, critical voices contend that marginal prices of the wholesale electricity market also contribute to the deficit by 
overcompensating hydro and nuclear sources owned by large private electricity producers with 'windfall benefits'. They also argue that deficit calculation procedures do not account for the fact that renewables reduce wholesale market prices through their very low operation costs (Fabra Utray, 2015; Victoria et al., 2015). In fact, it has been estimated that the spot price effect of renewables writes off a large portion of the subsidy received by these technologies in the form of feed-in tariffs (Ciarreta et al., 2014; Sáenz de Miera et al., 2008).

Despite various regulatory efforts, the 'electricity tariff deficit' has kept on increasing steadily. In order to avoid a burdensome one-off payment that would put public finances under further strain or result in a sudden, painful increase in consumer prices, the Spanish Government set up the Spanish Electricity Deficit Amortisation Fund (FADE) in 2010. This financial facility turns the accumulated deficit into fixed-income securities backed by payment rights to be progressively repaid by electricity consumers as a surcharge and bonds that are 'fully irrevocable and unconditionally guaranteed' by the state (Johanesson Linden et al., 2014). Given the scale of the accumulated debit (nearly three per cent of the Spanish GDP), the European Commission requested the Government 'ensure the effective elimination of deficit in the electricity system' in its recommendations for Spain's 2014 national reform and stability programme. The nature and purpose of these electricity deficit-related regulatory developments, which culminated in 2013 with an 'austerity-driven energy reform' (Espinosa Alejos, 2013), aimed at restoring the deteriorating financial stability of the sector, which suggests a complex yet patent entanglement of electricity pricing with macroeconomic decisionmaking in the context of the crisis.

\section{Growing energy poverty levels}

When analysed through the lens of 'objective' indicators based on HBS data, a clear trend of increasing energy-related hardship levels emerges - see Figure 2. The proportion of households whose energy burden is above certain thresholds grew progressively from 2007 following the evolution of household incomes and energy expenditure seen in Figure 1. Note that these are mostly households whose annual domestic energy expenditure as a proportion of income is above the average energy burden (around five per cent) for the period 2006-2012. As of 2012, 17 per cent of Spanish households spent more than 10 per cent of their income on domestic energy almost three times more households than in 2007. 
Figure 2: Proportion of Spanish households with an energy burden above certain thresholds, 2006-2012

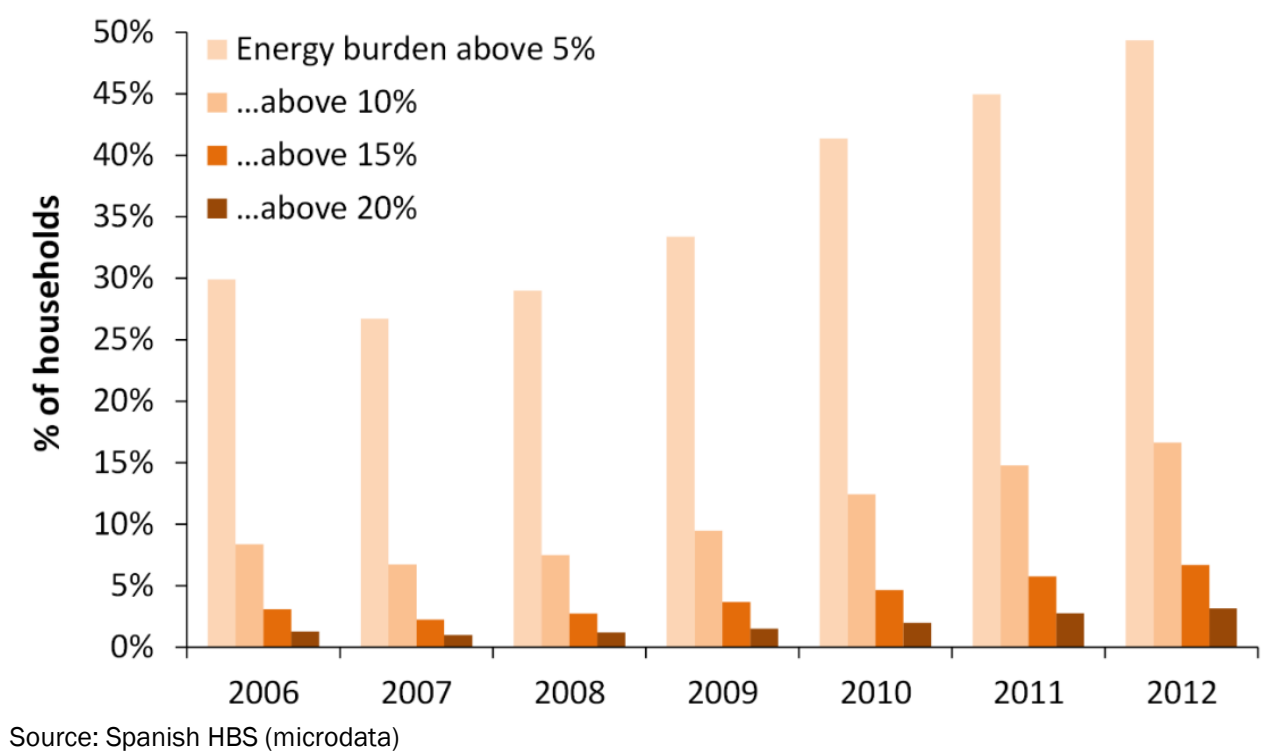

Self-reported indicators coming from EU SILC offer an analogous picture (see Figure 3). The share of households declaring themselves unable to keep their home adequately warm went from six to nine per cent between 2006 and 2012, while the percentage of households with arrears on utility bills increased from four to six per cent in the same period. These figures indicate a 50 per cent increase in the rate of households affected between 2006 and 2012 and a return to pre-2008 levels. In both indicators there was a drop in values during 2011, perhaps related to the fact that this was an exceptionally warm year with an average temperature of $1.4^{\circ} \mathrm{C}$ above normal values (AEMET, 2011). In addition, the share of households living in a dwelling with faults decreased substantially in 2011 and 2012 after the 2008-2010 increase. Furthermore, 25 per cent of households reported a dwelling that was not comfortably cool during summertime in 2007 and 2012 (Tirado Herrero et al., 2014). All these figures illustrate the variety of energy services and multiple vulnerabilities to be considered in the energy poverty framework. 
Figure 3: Proportion of Spanish households with self-reported energy poverty conditions, 2005-2012

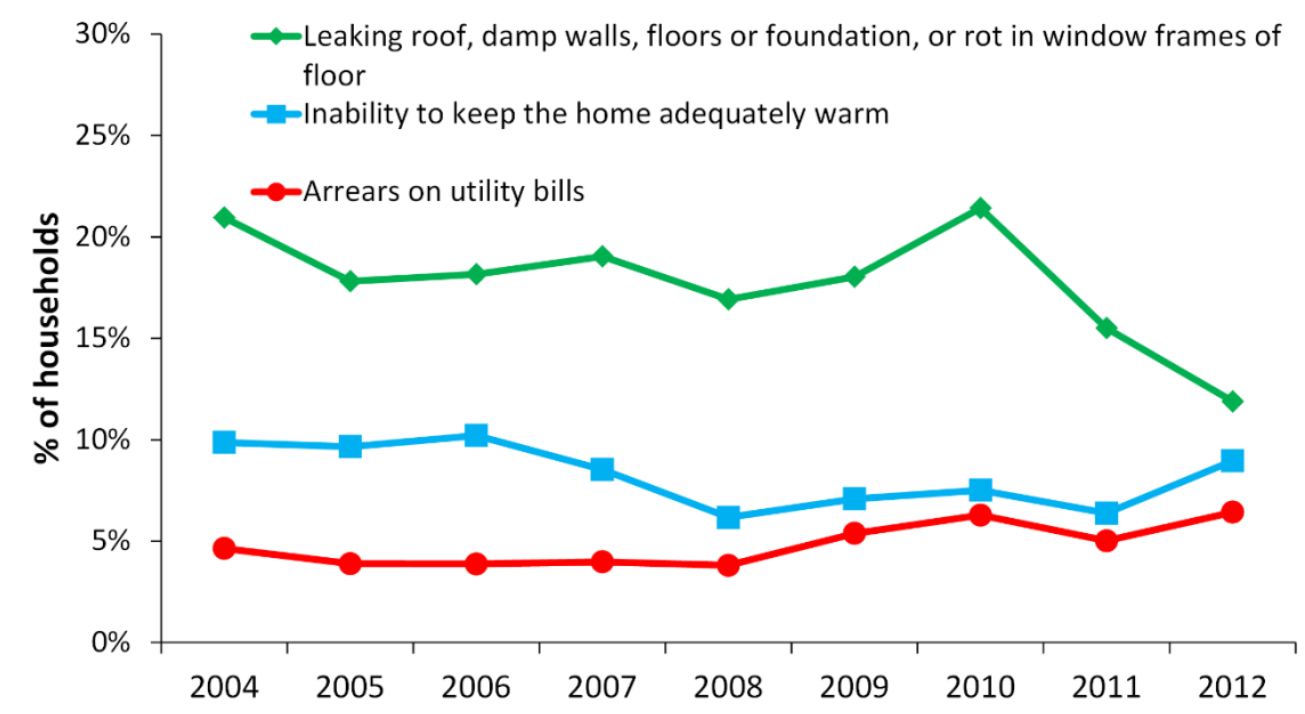

Source: Spanish SILC

It is worth noting that the number of households experiencing self-reported conditions in Spain seems to have declined drastically since the mid-1990s. Over 50 per cent of Spanish households were unable to keep their home adequately warm in 1994-1997 according to data from the European Community Household Panel (ECHP), the precursor of SILC (Healy, 2004). Interestingly this also occurred in a context of high unemployment after the post-1992 recession of the Spanish economy (Toharia, 1996).

\section{Uneven geographies of energy poverty: the effect of climate and unemployment}

The territorial size and diversity of Spain calls for national values to be disaggregated at a sub-national level with the purpose of identifying regional patterns within the country related to structural factors such as climate and socio-economic conditions. With this purpose, the energy poverty indicators were calculated for the 17 Spanish Autonomous Communities, and two Autonomous Cities (Ceuta and Melilla) are assessed against each other and against unemployment rates. This scale of analysis is policy-relevant given that key public services such as healthcare and education have been decentralised to regional Governments, which also have their own social welfare agenda and energy agencies.

The results of this comparative analysis based on 2012 data are presented in Figure 4. The graph shows a cluster of Autonomous Communities with domestic energy deprivation levels before the Spanish average for both selected indicators. It encompasses regions with high GDP per capita levels such as Madrid, the Basque Country or the Balearic Islands along with other less wealthy coastal regions and cities (Valencia, Canary Islands, Asturias, Ceuta and Melilla) where climatic factors may be playing a role in reducing wintertime space heating demand and energy expenditures. The lower right quadrant indicates that a larger proportion of households with an energy burden above 10 per cent does not always translate into greater levels of thermal discomfort. This is the case of Navarra, Aragón and La Rioja; regions with a GDP per capita above the Spanish average. The most affected constituencies, situated in the upper-left quadrant, report GDP per capita levels below the national average in all cases - in fact, Extremadura, Castilla-La Mancha, Andalusia and Murcia are in the 
bottom five of the 2012 ranking with regional income per head being almost half of the richest Autonomous Community (Basque Country).

It is worth noting that some of the worse-off regions are located in the warmer, drier parts of the country, which opens up the question of climatic conditions as a vulnerability factor through its influence in building design and performance. Even if milder winters reduce domestic energy needs, it is suspected that homes in Southern and Eastern Spain are more likely to lack central heating and be poorly insulated. In addition, warm regions also are more likely to report higher rates of indoor thermal discomfort in summertime. Thus an emerging set of vulnerabilities can be sensed in the context of the growing use of air conditioning, especially in Mediterranean Spain. Between 2000 and 2008 the share of households with air conditioning at home increased from 15.5 to 35.5 per cent, displacing yearly electricity consumption peak days from winter to summer (Blázquez et al., 2012).

Figure 4: Inability to keep the home adequately warm vs. energy burden above $10 \%$ (percentage of households for both indicators), Spanish Autonomous Communities 2012

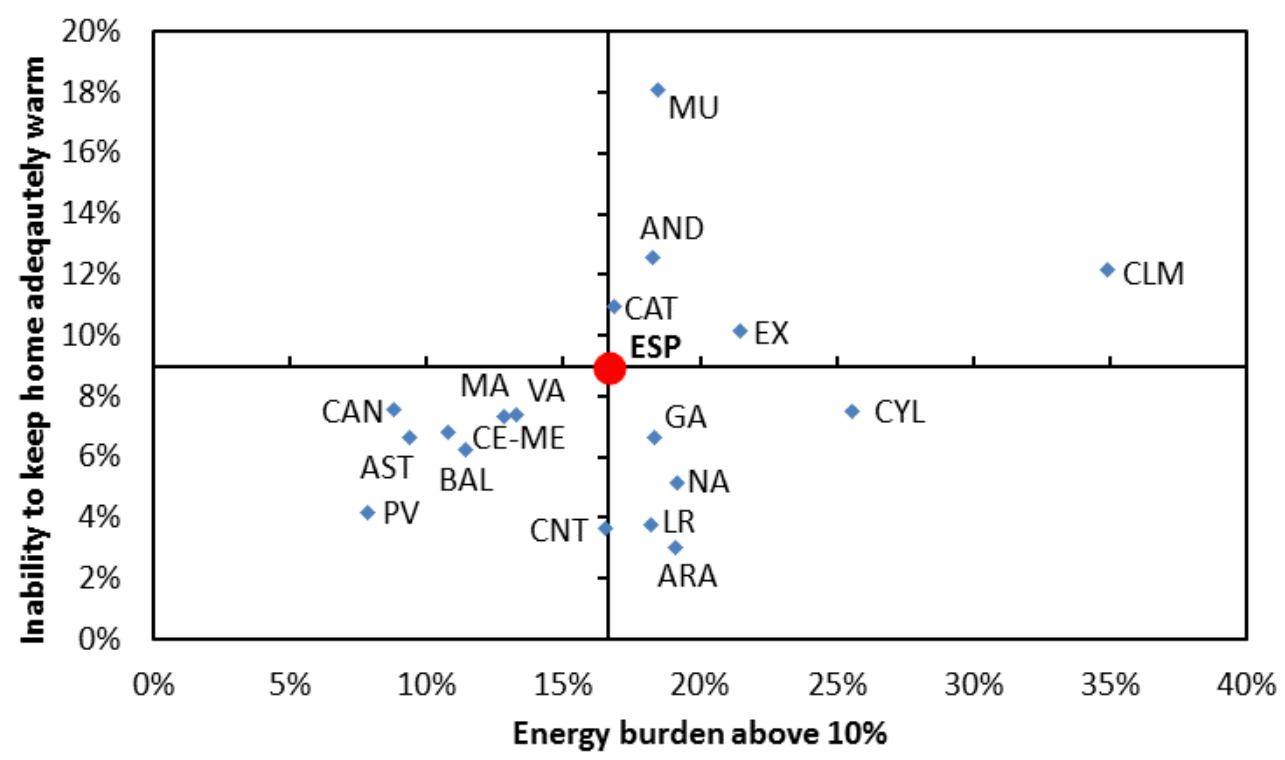

Source: Spanish SILC and Economically Active Population Survey

Legend: AND: Andalusia; ARA: Aragón; AST: Asturias; BAL: Balearic Islands; CAN: Canary Islands; CAT: Catalonia; CNT: Cantabria; CE-ME: Ceut-Melilla; CLM: Castila-La Mancha; CYM: Castilla y León; ESP: Spain (average); EX: Extremadura; GA: Galicia; LR: La Rioja; MA: Madrid; MU: Murcia; NA: Navara; PV: Basque Country; VA: Valencia.

The second part of the cross-regional analysis looks into the correlation between unemployment rates and energy poverty. A consequence of crisis- and austerityinduced recession, unemployment has been identified as a key driving factor of energy poverty in Spain throughout the crisis. Households whose head is unemployed perform systematically worse than other typologies in all indicators assessed. They also report the quickest and largest increase in the share of affected households, driving the nationwide increase of energy poverty levels that has occurred since 2008 (Tirado Herrero et al., 2014).

Linear correlation coefficients (Pearson's $r$ ) were calculated to explore possible links between energy poverty indicators and unemployment rates across Autonomous Communities in 2012. Statistically significant, relatively strong, positive relationships 


\section{p. 52. Energy poverty, crisis and austerity in Spain}

were found between the three self-reported SILC indicators and the unemployment rate (see Table 2). As expected, regions with higher unemployment contain a larger proportion of households with an enforced deficit of domestic energy services as indicated by SILC indicator 'inability to keep the home adequately warm', as shown in Figure 5.

Table 2: Linear correlation coefficientes between the unemployment rate and the scores of energy poverty indicators of Autonomous Communities, Spain 2012

\begin{tabular}{|l|c|}
\hline Indicator & Pearson's r \\
\hline Energy burden above 10\% & 0.07 \\
\hline Inability to keep the home adequately warm & $0.59 * *$ \\
\hline Arrears on utility bills & $0.67^{* *}$ \\
\hline Leaking roof, damp walls, floors or foundation, or rot in window frames of & $0.56^{*}$ \\
floor & \\
\hline Source: Spanish SILC and Economically Active Population Survey & \\
Note: ${ }^{*}$ significant at $p<0.05 ; * *$ significant at $p<0.01$ &
\end{tabular}

Figure 5: Inability to keep the home adequately warm vs. unemployment rate, Spanish Autonomous Communities 2012

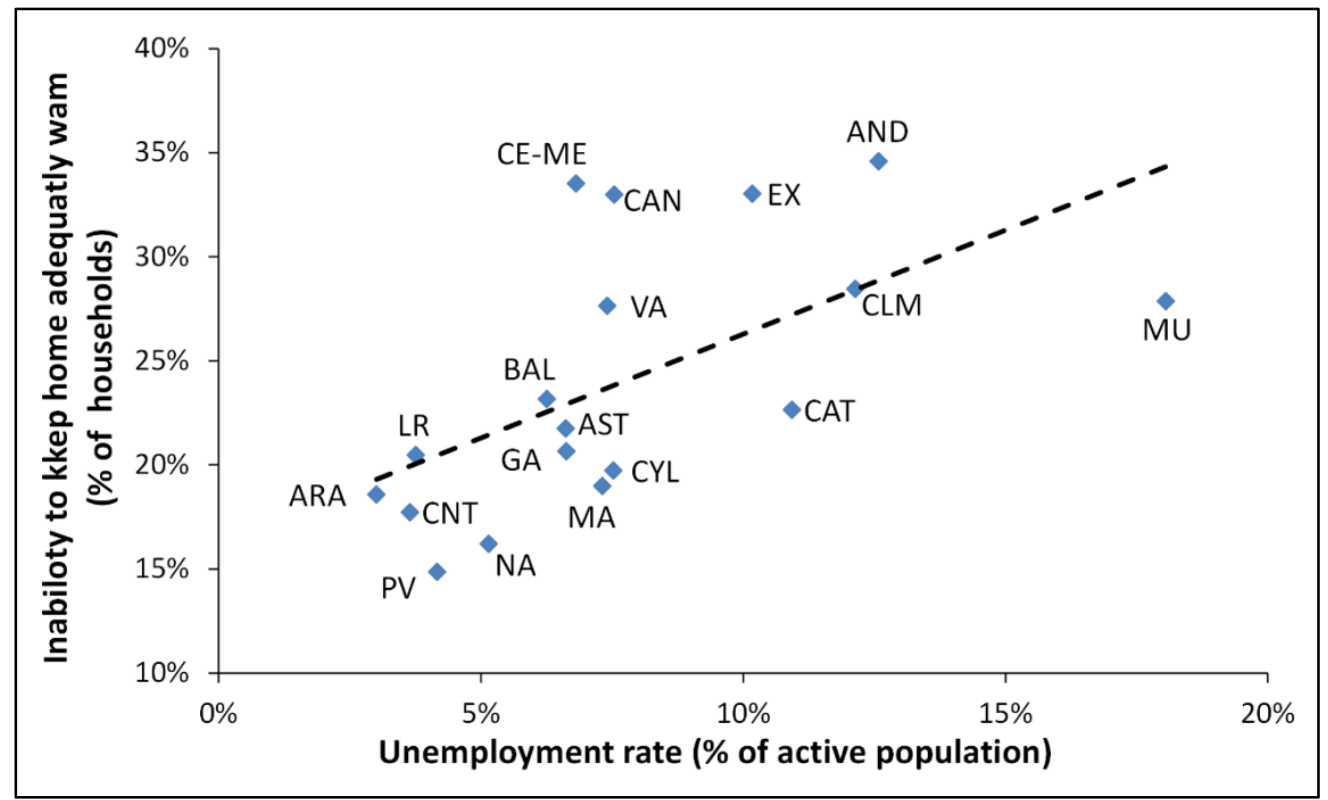

Source: Spanish SILC and Economically Active Population Survey

Legend: see Figure 4

\section{Conclusions}

The paper seeks to shed light on the largely under-researched connection between the post-2008 European debt crisis and energy poverty trends taking Spain as a case study. In doing so, we have explored the role played by economic recession and concomitant austerity as macro-level factors that have exacerbated pre-existing vulnerabilities in an unequal fashion. The evidence collected suggests that policies and decisions leading to the crisis and put forward in response to it have resulted in domestic energy deprivation impacts that go far beyond the purely macroeconomic effects of the economic downturn. A key contribution to the paper is unveiling the dynamic 
relationship between energy poverty levels, unemployment rates and domestic energy prices in that context.

In response to the first aim of the paper as stated in the introduction, we have found a sustained increase in energy poverty levels as measured by a range of expenditure-based and self-reported indicators. This trend is coherent with the decline in average household incomes and rapid increase in domestic energy prices and expenditures occurred in the same period. Despite some differences across indicators, the empirical analysis has revealed a tipping point around the year 2008 shown by the increase in all reported energy poverty metrics. However, the timing and direction of these trends may misleadingly convey the impression that energy poverty was a minor issue prior to the crisis. As shown by data for 2005, 2006 and 2007 - record years of the Spanish economic 'bonanza' - energy poverty is a persistent form of material deprivation rooted in structural factors such as the energy inefficiency of residential buildings and pre-2008 poverty and inequality levels. This challenges interpretations that favour a partial understanding of energy poverty as a by-product of the crisis that will be over once macroeconomic indicators reach pre-crisis levels.

As for its second aim, the paper has uncovered significant regional differences in the incidence of energy poverty across Spanish Autonomous Communities. These are likely to be related with uneven climatic and socio-economic conditions in a spatially diverse Spain. Some of the most affected regions are located in the milder Southern and Eastern front of the country, suggesting that the effect of climate is not straightforward but mediated through the energy efficiency of the residential fabric. It is suggested that the design, quality and energy-use features of dwellings are influenced by regional climatic conditions.

The reviewed evidence has identified unemployment a key short-term driver of domestic energy deprivation trends, also responsible for a significant part of the crossregional variation in energy poverty levels. Unemployment reduces the disposable income of laid-off workers and has depressing effects on the salaries of workers retaining their employment, new entrants and workers returning to the labour market. The effect of these changes has been unequally distributed with young, temporary and less qualified workers (especially those formerly employed in the construction sector) disproportionately bearing the burden of the adjustment.

A second short-term factor identified is electricity prices for domestic consumers. The reported 63 per cent nominal increase that occurred between 2007 and 2012 has put the energy budget of Spanish households under further pressure, especially of those using electricity for energy-intensive services like space heating and cooling. The politically contested character of regulated electricity pricing, including the controversial 'electricity tariff deficit', is another pathway through which crisis and austerity can be linked to growing domestic energy deprivation levels.

The paper presents energy poverty as a consequence of both structural and shortterm factors, encompassing different energy services and vulnerabilities and operating along wider social and spatial divides that the crisis has intensified. In contrast, the current national policy framework tends to offer linear, short-term, sometimes inadequately-targeted solutions. Such is the case of the bono social or social electricity tariff currently offering a 25 per cent rebate on the regulated price. Theoretically aimed at supporting 'vulnerable consumers', eligibility criteria do not however include income thresholds or the energy efficiency characteristics of dwellings, resulting in an unsatisfactory allocation of the discount with non-vulnerable households benefitting from the policy and vice versa. Similarly, energy efficiency schemes financed through public funds very seldom prioritise the disadvantaged as potentials recipients of support (Tirado Herrero et al., 2014). These shortcomings in policy definition can also 
be see in the EU's decision-making as well - see the suspected regressive effect of the ban on inefficient boilers recently decreed by the European Commission (Simon, 2015). They are instances of energy poverty-relevant measures which will enhance rather than reduce inequalities and vulnerabilities. When confronted with the complex, changing reality of energy poverty in pre- and post-crisis Spain and EU, the scale of societal and governance challenges lying ahead can be seen in their full extent.

* Correspondence address: Sergio Tirado Herrero, RMIT Europe, Carrer de Minerva, 2, 08006 Barcelona (Spain). Email: sergio.tirado@rmit.edu.au

\section{References}

AEMET (2011) Resumen Anual Climatológico 2011. Agencia Estatal de Meteorología. Ministerio de Agricultura, Alimentación y Medio Ambiente.

Blázquez, L., Boogen, N., Filippini, M., (2012) Residential electricity demand for Spain: new empirical evidence using aggregated data (No. CEPE Working Paper No. 82). Zürich: Centre for Energy Policy and Economics. Swiss Federal Institutes of Technology.

Bouzarovski, S. and Petrova, S. (2015) A global perspective on domestic energy deprivation: Overcoming the energy poverty-fuel poverty binary. Energy Research and Social Science, Vol 10, 31-40. DOI:10.1016/j.erss.2015.06.007.

Bouzarovski, S. and Tirado Herrero, S. (2015) The energy divide: Integrating energy transitions, regional inequalities and poverty trends in the European Union. European Urban and Regional Studies. DOI: 10.1177/0969776415596449.

Carballo-Cruz, F. (2011) Causes and consequences of the Spanish economic crisis: Why the recovery is taken so long? Panoeconomicus, 58, 309-328. DOI: 10.2298/PAN1103309C.

Ciarreta, A., Espinosa, M.P. and Pizarro-Irizar, C. (2014) Is green energy expensive? Empirical evidence from the Spanish electricity market. Energy Policy, 69, $205-$ 215. DOI:10.1016/j.enpol.2014.02.025

Dagoumas, A. and Kitsios, F. (2014) Assessing the impact of the economic crisis on energy poverty in Greece. Sustain. Cities Soc, 13, 267-278. DOI: 10.1016/j.scs.2014.02.004.

Espinosa Alejos, M.P. (2013) An austerity-driven energy reform. Span. Econ. Financ. Outlook, 2, 51-60.

European Commission (2014) Recommendation for a Council Recommendation on Spain's 2014 national reform programme and delivering a Council opinion on Spain's 2014 stability programme (No. COM(2014) 410 final). Brussels.

Fabra Utray, J. (2015) El déficit tarifario: sin un diagnóstico correcto nunca habrá una reforma eficiente. [WWW Document]. Econ. Frente Crisis. URL https://economistasfrentealacrisis.wordpress.com/2012/11/08/el-deficittarifario-sin-un-diagnostico-correcto-nunca-habra-una-reforma-eficiente/

Falkner, R. (2014) Global environmental politics and energy: Mapping the research agenda. Energy Res. Soc. Sci., 1, 188-197. DOI:10.1016/j.erss.2014.03.008

García Serrano, C. (2011) Dejà vu? Crisis de empleo y reformas laborales en España. Rev. Econ. Apl., 56, 149-177.

Gili, M., Roca, M., Basu, S., McKee, M. and Stuckler, D. (2013) The mental health risks of economic crisis in Spain: evidence from primary care centres, 2006 and 2010. Eur. J. Public Health, 23, 103-108. DOI:10.1093/eurpub/cks035

Healy, J.D. (2004) Housing, fuel poverty, and health: a pan-European analysis. Ashgate Pub, Aldershot, England; Burlington, VT. 
Hills, J. (2012) Getting the measure of fuel poverty. Final Report of the Fuel Poverty Review, CASE report 72. Centre for Analysis of Social Exclusion. The London School of Economics and Political Science. London: UK.

INE (2015) Tasas de paro por sexo y grupo de edad [WWW Document]. Inst. Nac. Estad. Available at: http://www.ine.es/dyngs/INEbase/es/operacion.htm?c= Estadistica_C\&cid=1254736176918\&menu=ultiDatos\&idp=1254735976595 (Accessed: 09/25/2015).

Johanesson Linden, A., Kalantzis, F., Maincent, E. and Pienkowski, J. (2014) Electricity Tariff Deficit: Temporary or Permanent Problem in the EU? (No. Economic Papers 534). European Comission.

Katsoulakos, N. (2011) Combating Energy Poverty in Mountainous Areas Through Energy-saving Interventions: Insights From Metsovo, Greece. Mt. Res. Dev. 31, 284-292. DOI:10.1659/MRD-JOURNAL-D-11-00049.1

Knight, D.M. (2014) A Critical Perspective on Economy, Modernity and Temporality in Contemporary Greece through the Prism of Energy Practice (No. GreeSE Paper No . 81), Hellenic Observatory Papers on Greece and Southeast Europe. The London School of Economics and Political Science.

Martín Urriza, C., Zarauz Puertas, L. and Lago Peñas, J.M. (2015) En Clave de Economía (No. 2/2015). Comisiones Obreras.

Nolay, P. (2009) EPEE project: European fuel Poverty and Energy Efficiency. Alphéeis.

Orsini, K. (2014) Wage adjustment in Spain: slow, inefficient and unfair? ECFIN Ctry. Focus 11.

Petrova, S., Gentile, M., MÃăkinen, I.H. and Bouzarovski, S. (2013) Perceptions of thermal comfort and housing quality: exploring the microgeographies of energy poverty in Stakhanov, Ukraine. Environ. Plan. A, 45, 1240-1257. DOI:10.1068/a45132

Romero, J.C., Linares, P., López Otero, X., Labandeira, X. and Pérez Alonso, A. (2014) Pobreza Energética en España. Análisis económico y propuestas de actuación. Economics for Energy.

Sáenz de Miera, G., del Río González, P. and Vizcaíno, I. (2008) Analysing the impact of renewable electricity support schemes on power prices: The case of wind electricity in Spain. Energy Policy, 36, 3345-3359. DOI:10.1016/j.enpol.2008.04.022

Santamouris, M., Paravantis, J.A., Founda, D., Kolokotsa, D., Michalakakou, P., Papadopoulos, A.M., Kontoulis, N., Tzavali, A., Stigka, E.K., Ioannidis, Z., Mehilli, A., Matthiessen, A. and Servou, E. (2013) Financial crisis and energy consumption: A household survey in Greece. Energy Build. 65, 477-487. DOI:10.1016/j.enbuild.2013.06.024

Santillán Cabeza, S.E. (2010) Energy poverty - the impact of liberalisation and the economic crisis (Opinion of the European Economic and Social Committee (Exploratory opinion) No. TEN/420). Brussels.

Simon, F. (2015) EU ban on aging boilers expected to bring "mammoth" energy savings. Euractiv.com.

Thomson, H. and Snell, C. (2013) Quantifying the prevalence of fuel poverty across the European Union. Energy Policy, 52, 563-572. DOI:10.1016/j.enpol.2012.10.009

Tirado Herrero, S., Jiménez Meneses, L., López Fernández, J.L., Martín García, J., and Perero Van Hove, E. (2014) Pobreza energética en España. Análisis de tendencias. Madrid, Spain: Asociación de Ciencias Ambientales.

Tirado Herrero, S., López Fernández, J.L. and Martín García, P. (2012) Pobreza energética en España, Potencial de generación de empleo directo de la pobreza derivado de la rehabilitación energética de viviendas. Madrid, Spain: Asociación de Ciencias Ambientales.

Toharia, L., (1996) Empleo y paro en España. Evolución, situación y perspectivas. Ekon. Rev. Vasca Econ. 35, 36-67. 
p. 56. Energy poverty, crisis and austerity in Spain

Urbanos-Garrido, R.M. and Lopez-Valcarcel, B.G. (2015) The influence of the economic crisis on the association between unemployment and health: an empirical analysis for Spain. Eur. J. Health Econ.

Victoria, M., Velasco, J.L. and del Río, R. (2015) ¿Hay que pagar el déficit de tarifa? [WWW Document]. URL http://blogs.publico.es/dominiopublico/11295/hay-quepagar-el-deficit-de-tarifa/ 